\title{
NOTES
}

\section{Synthesis of Mannose Branched Deoxy-Glucan Derivative by Polymerization of Disaccharide Monomer}

\author{
Kenichi Hatanaka, ${ }^{\dagger}$ Tetsuo Yamaguchi, ${ }^{*}$ Kohsaku OKuYama, \\ Kaname KATSURAYA, and Kazuhiko HASHIMOTO* \\ Institute of Industrial Science, University of Tokyo, \\ 7-22-1 Roppongi, Minato-ku, Tokyo 106-8558, Japan \\ ${ }^{*}$ Faculty of Engineering, Kogakuin University, \\ 2665-1 Nakano-cho, Hachioji, Tokyo 192-0015, Japan
}

(Received May 1, 2000; Accepted July 9, 2000)

KEY WORDS Anhydrosugar / Ring-Opening Polymerization / Branched Glycan / Heteropolysaccharide /

Natural branched polysaccharides show various biological activities owing to branching sugars. There are two synthetic methods for branched polysaccharides, glycosylation of linear polysaccharide derivative $\mathrm{i}^{1-5}$ and polymerization of disaccharide derivative. ${ }^{6-9}$ By glycosylation of linear polysaccharide derivative, all sugar units must be glycosylated stereoselectively to synthesize a polysaccharide with branching of $100 \%$. Polymerization of disaccharide derivative always gives combshaped polysaccharide except for the non-polymerizable monomers.

Polymerizability of anhydro-disaccharide monomer such as cellobiose and maltose derivatives is low. Only mannosylated 1,6-anhydro-mannose monomer and glucosylated 1,6-anhydro-2-deoxy-glucose monomer polymerize to give comb-shaped polysaccharides. ${ }^{8,9}$

In the polymerization of 1,6-anhydro-3-O-benzyl-2deoxy-4-O- $\left(2^{\prime}, 3^{\prime}, 4^{\prime}, 6^{\prime}\right.$-tetra-O-benzyl- $\alpha$-D-glucopyranosyl)- $\beta$-D-arabino-hexopyranose, ${ }^{9}$ comb-shaped polysaccharide derivative was obtained at the lower temperature and cyclic trimer (hexasaccharide derivative) was given at higher temperature for longer polymerization time.

In this study, 1,6-anhydro-3-O-benzyl-2-deoxy-4-O$\left(2^{\prime}, 3^{\prime}, 4^{\prime}, 6^{\prime}\right.$-tetra-O-benzyl- $\alpha$-D-mannopyranosyl)- $\beta$-Darabino-hexopyranose was synthesized and polymerized with a Lewis acid to clarify the effects of branching sugar unit on the polymerization and cyclization reactions.

\section{EXPERIMENTAL}

\section{General Methods}

${ }^{1} \mathrm{H}$ and ${ }^{13} \mathrm{C}$ nuclear magnetic resonance (NMR) spectra were obtained with JEOL JNM LA-500 spectrometers for solutions in chloroform- $d$ with tetramethylsilane as internal standard. Gel permeation chromatography (GPC) of the polymerization products was carried out on a Shimadzu LC $10 \mathrm{AD}$ liquid chromatograph (TOSOH Multipore $\mathrm{H}_{\mathrm{XL}}-\mathrm{M} \times 3$ columns or $\mathrm{G} 2000 \mathrm{H}_{\mathrm{XL}}+\mathrm{G} 1000 \mathrm{H}_{\mathrm{XL}}$ columns) using chloroform as solvent and polystyrene

\footnotetext{
${ }^{\dagger}$ To whom correspondence should be addressed.
}

standards. Optical rotations were measured for solutions in chloroform at $25^{\circ} \mathrm{C}$ using a Perkin-Elmer Model 241 polarimeter. Merck silica gel was used for column chromatography.

1,6:2,3-Dianhydro-4-O- $\left(2^{\prime}, 3^{\prime}, 4^{\prime}, 6^{\prime}\right.$-tetra-O-benzyl- $\alpha-D$ mannopyranosyl)- $\beta$-D-mannopyranose (glycosylation)

1,6:2,3-Dianhydro- $\beta$-D-mannopyranose $\quad(0.2 \mathrm{~g}, \quad 1.4$ mmol) prepared from 1,6-anhydro- $\beta$-D-glucopyranose according to Cerny's method ${ }^{10,11}$ and 2,3,4,6-tetra-Obenzyl- $\alpha$-D-mannopyranosyl trichloroacetimidate $(1.4 \mathrm{~g}$, $2.1 \mathrm{mmol}$ ) were dissolved in $25 \mathrm{~mL}$ of dry dichloromethane. Molecular sieve $4 \mathrm{~A}$ was added to the solution and the reaction mixture was stirred at $-5^{\circ} \mathrm{C}$ for several min. After dropwise addition of $t$-butyldimethylsilyl trifluoromethansulfonate (TBDMS triflate, $0.3 \mathrm{~mL}$ ), the mixture was stirred at $-5^{\circ} \mathrm{C}$ for $60 \mathrm{~min}$. The molecular sieve was removed by filtration and $30 \mathrm{~mL}$ of chloroform was added to the filtrate. The solution was neutralized with aqueous sodium hydrogen carbonate until $\mathrm{pH}=7$, washed with water and aqueous sodium chloride and dried with anhydrous sodium sulfate. After concentrating, the residue was subjected to column chromatography ( $n$-hexane: ethyl acetate $=4: 1, \mathrm{v} / \mathrm{v}$ ). Yield $0.41 \mathrm{~g}$ $(44.8 \%)$.

1,6-Anhydro-3-O-benzyl-2-deoxy-4-O- $\left(2^{\prime}, 3^{\prime}, 4^{\prime}, 6^{\prime}\right.$-tetra-Obenzyl- $\alpha$-D-mannopyranosyl) - $\beta$-D-arabino-hexopyranose (1)

2,3-Epoxide scission of 1,6:2,3-dianhydro-4-O-(2',3', $4^{\prime}, 6^{\prime}$-tetra-O-benzyl- $\alpha$-D-mannopyranosyl)- $\beta$-D-mannopyranose with lithium aluminum hydride according to Seib's procedure ${ }^{12}$ was carried out as follows. To a solution of 1,6:2,3-dianhydro-4-O-(2',3',4',6'-tetra-O-benzyl$\alpha$-D-mannopyranosyl)- $\beta$-D-mannopyranose (1.04 g, 1.5 $\mathrm{mmol}$ ) in tetrahydrofuran (THF) $(80 \mathrm{~mL})$ was added lithium aluminum hydride $(0.59 \mathrm{~g})$ and the reaction mixture was stirred at $40^{\circ} \mathrm{C}$ for $3 \mathrm{~h}$. Excess lithium aluminum hydride was eliminated by careful addition of ethyl acetate. The resulting mixture was stirred under air overnight to eliminate lithium aluminum hydride completely. The precipitate was filtered off and washed well with THF, and the THF filtrate was evaporated in vacuo. The syr- 

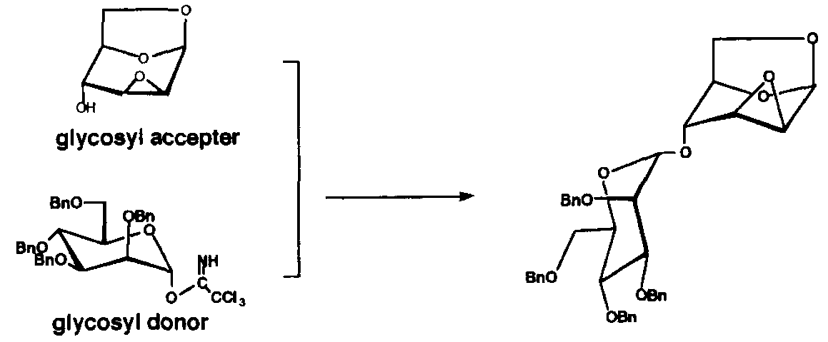

Scheme 1. Glycosylation of dianhydrosugar with mannosyl imidate.

upy product was dissolved in chloroform, and the solution was washed with water and aqueous sodium chloride and dried with anhydrous sodium sulfate. Purification of 1,6-anhydro-2-deoxy-4-O- $\left(2^{\prime}, 3^{\prime}, 4^{\prime}, 6^{\prime}\right.$-tetra-Obenzyl- $\alpha$-D-mannopyranosyl)- $\beta$-D-arabino-hexopyranose was carried out by column chromatography ( $n$-hexane: ethyl acetate $=1: 1, \mathrm{v} / \mathrm{v}$ ).

To a solution of the obtained 1,6-anhydro-2-deoxy-4-O( $2^{\prime}, 3^{\prime}, 4^{\prime}, 6^{\prime}$-tetra-O-benzyl- $\alpha$-D-mannopyranosyl ) $-\beta$-Darabino-hexopyranose $(0.73 \mathrm{~g}, 1.1 \mathrm{mmol})$ in dried $N, N$ dimethylformamide (DMF), was added sodium hydride $(0.08 \mathrm{~g})$, and the mixture was stirred vigorously at room temperature. After $1 \mathrm{~h}, 0.54 \mathrm{~mL}$ of benzyl bromide was added to the mixture at $0^{\circ} \mathrm{C}$, and the reaction mixture was stirred at $0^{\circ} \mathrm{C}$ for $2 \mathrm{~h}$. The unreacted sodium hydride was removed by filtration and $30 \mathrm{~mL}$ chloroform was added to the filtrate. The solution was washed with water and aqueous sodium chloride, and dried with anhydrous sodium sulfate. After concentrating, the residue was subjected to column chromatography ( $n$-hexane: ethyl acetate $=3: 1, \mathrm{v} / \mathrm{v})$. Yield $0.57 \mathrm{~g}(46.6 \%) .{ }^{1} \mathrm{H}$ NMR: 1.75 (d, 1H, H-2eq, $J_{2 \mathrm{eq}, 2 \mathrm{ax}}=14.1 \mathrm{~Hz}$ ), 1.80 (ddd, $1 \mathrm{H}, \mathrm{H}-2$ ax, $\left.J_{1,2 \mathrm{ax}}=1.5 \mathrm{~Hz}, J_{2 \mathrm{ax}, 3}=6.1 \mathrm{~Hz}\right), 3.27(\mathrm{~d}, 1 \mathrm{H}, \mathrm{H}-3), 3.51$ (t, 1H, H-6ex), 3.57 (s, 1H, H-4), $3.64\left(\mathrm{~s}, 1 \mathrm{H}, \mathrm{H}-2^{\prime}\right), 3.67$ (s, 2H, H-6'), 3.86 (s, 3 H, H-3', H-4', H-5'), 4.03 (d, 1H, H-6en, $\left.J_{6 \mathrm{ex}, 6 \mathrm{en}}=7.3 \mathrm{~Hz}\right), 4.50(\mathrm{~d}, 1 \mathrm{H}, \mathrm{H}-5), 4.79(\mathrm{~s}, 1 \mathrm{H}, \mathrm{H}-$ $\left.1^{\prime}\right), 4.35-4.79\left(\mathrm{~m}, 10 \mathrm{H},-\mathrm{CH}_{2} \mathrm{Ph}\right), 5.42(\mathrm{~s}, 1 \mathrm{H}, \mathrm{H}-1), 7.07$ -7.26 (m, $25 \mathrm{H}$, aromatic protons), ${ }^{13} \mathrm{C} \mathrm{NMR}: 33.01$ (1C, $\mathrm{C}-2), 64.79(1 \mathrm{C}, \mathrm{C}-6), 69.33$ (1C, $\left.\mathrm{C}-6^{\prime}\right), 70.87\left(1 \mathrm{C},-\mathrm{CH}_{2} \mathrm{Ph}\right.$ at C-3), $71.79(1 \mathrm{C}, \mathrm{C}-3), 72.22\left(1 \mathrm{C}, \mathrm{C}-5^{\prime}\right), 72.43\left(1 \mathrm{C},-\mathrm{CH}_{2}-\right.$ $\mathrm{Ph}$ at $\left.\mathrm{C}-3^{\prime}\right), 72.77\left(1 \mathrm{C},-\mathrm{CH}_{2} \mathrm{Ph}\right.$ at $\left.\mathrm{C}-2^{\prime}\right), 73.26\left(1 \mathrm{C},-\mathrm{CH}_{2}-\right.$ $\mathrm{Ph}$ at C-6'), 74.61 (1C, C-5), 74.77 (1C, C-4), 75.00 (3C, C$2^{\prime}, \mathrm{C}-4^{\prime},-\mathrm{CH}_{2} \mathrm{Ph}$ at C-4'), $77.11\left(\mathrm{t}, \mathrm{CDCl}_{3}\right), 80.01$ (1C, C-3 '), 97.76 (1C, C-1'), 99.59 (1C, C-1), 127.48-128.43, and 137.95-138.42 (aromatic carbons).

\section{Polymerization of 1}

Ring-opening polymerization of 1 was carried out with phosphorus pentafluoride as initiator as described previously. ${ }^{9}$

\section{RESULTS AND DISCUSSION}

\section{Glycosylation}

In our previous investigation, ${ }^{13}$ the glycosylation of 1,6:2,3-dianhydro- $\beta$-D-mannopyranose and 2,3,4,6-tetraO-benzyl- $\beta$-D-glucopyranosyl trichloroacetimidate at room temperature for $5 \mathrm{~h}$ and at $-30^{\circ} \mathrm{C}$ for $15 \mathrm{~min}$ provided thermodynamically stable $\alpha$-glycoside and kinetically preferred $\beta$-glycoside. But, when $2,3,4,6$-tetra-Obenzyl- $\alpha$-D-mannopyranosyl trichloroacetimidate was

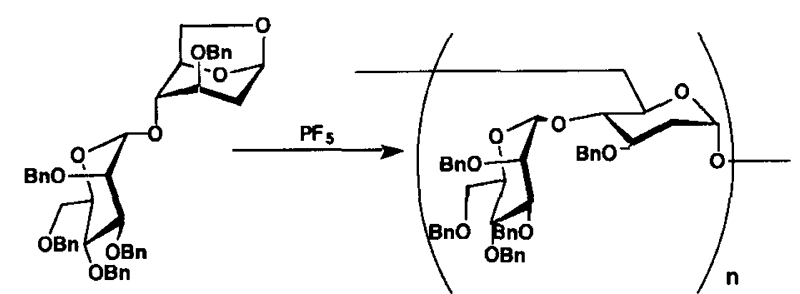

Scheme 2. Ring-opening polymerization of disaccharide monomer.

used as a glycosyl donor in this study, longer reaction time of glycosylation gave by-products in quantity. Therefore, glycosylation was carried out at $-5^{\circ} \mathrm{C}$ for 60 min in spite of low yield. The amount of catalyst (TBDMS triflate) had no effect on yield. Since the neutralized solution of the crude mixture of the products was unstable, rapid purification by column chromatography was necessary.

In the $\mathrm{H}-\mathrm{H}$ correlation spectroscopy (COSY)-FG (field gradient pulse) spectrum of 1,6:2,3-dianhydro-4-O-( $\left(2^{\prime}, 3^{\prime}\right.$, $4^{\prime}, 6^{\prime}$-tetra-O-benzyl- $\alpha$-D-mannopyranosyl ) - $\beta$-D-mannopyranose, $\mathrm{H}-3$ did not show the crosspeak with $\mathrm{H}-4$ in spite of the anti relationship between $\mathrm{H}-3$ and $\mathrm{H}-4$ in $\mathrm{C} 1$ conformation. $\mathrm{H}-3$ is strongly related to $\mathrm{H}-5$ with long range interaction. The pyranose ring may thus have a slightly planar structure rather than chair-form conformation probably because a large axial O-benzyl group at $\mathrm{C}-2$ made the conformation of the pyranose ring was distorted.

\section{Ring-Opening Polymerization}

Cationic ring-opening polymerization of 1 with phosphorus pentafluoride as initiator was conducted. The results are summarized in Table I. Polymerization at -78 ${ }^{\circ} \mathrm{C}$ gave the polymer with number average molecular weight of 26000 (polystyrene standard) indicating a linear polymer. For the ${ }^{13} \mathrm{C}$ NMR spectrum of the polymer, only two peaks were found in the anomeric carbon region, indicating that the obtained polymer (mannosebranched deoxyglucan derivative) had a regular structure. The ${ }^{1} \mathrm{H}$ NMR spectrum of the polymer showed two singlet peaks at 5.46 and $4.95 \mathrm{ppm}$, which were assigned to $\mathrm{H}-1$ (deoxyglucose) and $\mathrm{H}-1^{\prime}$ (mannose), respectively. The coupling constant $\left(J_{1,2 \mathrm{ax}}\right)$ of 2 -deoxy- $\beta$-D-arabinohexopyranoside derivative must be large $(6 \mathrm{~Hz}-10 \mathrm{~Hz})$, because $\mathrm{H}-1$ and $\mathrm{H}-2 \mathrm{ax}$ should have anti relationship. The obtained polymer was thus an $\alpha$-linked polysaccharide derivative, since the coupling constant $\left(J_{1,2 \mathrm{ax}}\right)$ was small ( $\mathrm{H}-1$ peak was singlet). Chemical shift of anomeric carbon of the sugar unit in the main chain (2-deoxy-Darabino-hexopyranose) in the ${ }^{13} \mathrm{C} \mathrm{NMR}$ spectrum was $99.83 \mathrm{ppm}$ which was similar to the chemical shift of C-1 of $\alpha$ - $(1 \rightarrow 6)$-linked 2-deoxy-4-O-(2', $3^{\prime}, 4^{\prime}, 6^{\prime}$-tetra-O-benzyl- $\alpha$-D-glucopyranosyl)-D-arabino-hexopyranan $\quad(99.74$ ppm), ${ }^{9}$ supporting $\alpha$-stereoregularity. It was concluded that polymerization at $-78^{\circ} \mathrm{C}$ provides the stereoregular comb-shaped 3-O-benzyl-2-deoxy-4-O-(2',3',4',6'-tetra-Obenzyl- $\alpha$-D-mannopyranosyl )-( $1 \rightarrow 6$ )- $\alpha$-D-arabino-hexopyranan. Polymerizability of 1 was quite high as well as mannose-branched mannose monomer, ${ }^{8}$ since 1,6anhydro-2-equatorialsubstituted- and 1,6-anhydro-2-de- 
Table I. Ring-opening polymerization of 1,6-anhydro-3-O-benzyl-2-deoxy-4-O-(2', $3^{\prime}, 4^{\prime}, 6^{\prime}$-tetra-O-benzyl- $\alpha$-D-mannopyranosyl)

\begin{tabular}{|c|c|c|c|c|c|c|c|c|}
\hline No. & $\frac{\text { Monomer }}{\mathrm{mg}}$ & $\frac{\text { Solvent }}{\mathrm{mL}}$ & $\frac{\text { Initiator }}{\text { mol\% }}$ & $\frac{\text { Temp. }}{{ }^{\circ} \mathrm{C}}$ & $\frac{\text { Time }}{\mathrm{h}}$ & $\frac{\text { Yield }}{\%}$ & $\begin{array}{l}M_{\mathrm{n}}{ }^{\mathrm{b}} \\
\times 10^{3}\end{array}$ & $\frac{[\alpha]_{D}}{\operatorname{deg}}$ \\
\hline 1 & 200 & 0.5 & 20 & -78 & 24 & 85.4 & 26.0 & +62.3 \\
\hline 2 & 200 & 0.5 & 20 & 0 & 24 & 33.3 & 2.1 & n.d. \\
\hline
\end{tabular}

${ }^{\mathrm{a}}$ Solvent, dichloromethane; initiator $\mathrm{PF}_{5} .{ }^{\mathrm{b}}$ Determined by GPC (polystyrene standard).

oxy- were not strically hindered monomers.

Polymerization at a higher temperature of $0^{\circ} \mathrm{C}$ gave only the oligomer in $33 \%$ yield. ${ }^{13} \mathrm{C}$ NMR spectral results showed seven peaks in the region of $95-98 \mathrm{ppm}$ and other seven peaks at $99-101 \mathrm{ppm}$, corresponding to anomeric carbon atoms of the branching unit and sugar unit in the main chain, respectively. The obtained oligomer thus has irregular structures and/or is mixture of several compounds. There was no or a small amount of cyclic oligomer. The polymerization of 1 at $0^{\circ} \mathrm{C}$ is thus quite different from that of 1,6-anhydro-3-O-benzyl-2deoxy-4-O- ( $2^{\prime}, 3^{\prime}, 4^{\prime}, 6^{\prime}$-tetra-O-benzyl- $\alpha$-D-glucopyranosyl)- $\beta$-D-arabino-hexopyranose which mainly gave the cyclic oligosaccharide at $0^{\circ} \mathrm{C} .{ }^{13}$ The difference in branching unit of the anhydrosugar monomer resulted in a very different oligomeric product at $0^{\circ} \mathrm{C}$. The mannosebranched monomer hardly gave a cyclic trimer probably because of steric hindrance of the axial benzyloxy group at C-2.

Acknowledgments. This work was supported by Yamada Science Foundation.

\section{REFERENCES}

1. H. Ito and C. Schuerch, J. Am. Chem. Soc., 101, 5797 (1979).

2. T. Uryu, M. Yamanaka, M. Henmi, K. Hatanaka, and K. Matsuzaki, Carbohydr. Res., 157, 157 (1986).

3. K. Hatanaka, S. -C. Song, A. Maruyama, T. Akaike, A. Kobayashi, and H. Kuzuhara, J. Carbohydr. Chem., 11, 1027 (1992).

4. K. Hatanaka, S. Ohta, T. Kadokura, and M. C. Kasuya, Kobunshi Ronbunshu, 54, 947 (1997).

5. K. Hatanaka, S. Ohta, M. C. Kasuya, and K. Kanno, Nippon Kagaku Kaishi, 757 (1998).

6. B. Vernovic and C. Schuerch, Carbohydr. Res., 14, 199 (1970).

7. V. Masura and C. Schuerch, Carbohydr. Res., 15, 65 (1970).

8. K. Kobayashi, K. Nomura, and M. Okada, Carbohydr. Res., 242, 161 (1993).

9. M. C. Kasuya and K. Hatanaka, Macromolecules, 32, 2131 (1999).

10. M. Cerny, L. Kaldova, and J. Pacak, Collect. Czech. Chem. Commun., 33, 1143 (1968).

11. T. Trnka and M. Cerny, Collect. Czech. Chem. Commun., 36, 2216 (1971).

12. P. A. Seib, J. Chem. Soc. (C), 2552 (1969).

13. M. C. Kasuya and K. Hatanaka, Tetrahedron Lett., 39, 9719 (1998). 